\title{
Mapeamento Tecnológico dos Anticorpos Conjugados no Tratamento das Doenças Crônicas: Câncer
}

\section{Technological Mapping of Conjugated Antibodies in the Treatment of Chronic Diseases: Cancer}

\author{
Lana Grasiela Alves Marques ${ }^{1}$ \\ Fátima de Cássia Evangelista de Oliveira ${ }^{2}$ \\ Rejane Ramos de Machado ${ }^{1}$ \\ Lidiane dos Santos Carvalho ${ }^{1}$ \\ Claudia do Ó Pessoa ${ }^{2}$ \\ ${ }^{1}$ Fundação Oswaldo Cruz, Rio de Janeiro, RJ, Brasil \\ ${ }^{2}$ Universidade Federal do Ceará, Fortaleza, CE, Brasil
}

\begin{abstract}
Resumo
Anticorpos conjugados são moléculas criadas pela fusão (química e biológica) de moléculas diferentes, com a ação farmacológica, em geral, distintas entre si. Tem como finalidade entregar de forma seletiva drogas bastante potentes citotoxicamente nas células tumorais, promovendo uma ação-alvo dirigida e minimizando os efeitos colaterais. O presente trabalho tem como objetivo realizar um levantamento das tecnologias que estão protegidas por meio dos direitos de patentes com anticorpos conjugados (ADCs). Para o mapeamento da informação tecnológica, foram utilizadas as bases de dados Derwent Innovations Index, LENS.ORG, Inteligência Competitiva da Cortellis e a base de dados do Instituto Nacional de Propriedade Industrial (INPI). Os dez países que mais depositaram patentes são os Estados Unidos, com 416 patentes; a China (149); e o Canadá (92). O Brasil possui 11 depósitos de patentes, porém apenas uma como residente.
\end{abstract}

Palavras-chave: Anticorpos. Neoplasia. Patentes.

\begin{abstract}
Conjugated antibodies are molecules created by the fusion (chemical and biological) of different molecules, with the pharmacological action, in general, distinct from each other. Its purpose is to selectively deliver very potent cytotoxic drugs in tumor cells, promoting a target action, minimizing side effects. The present work aims to carry out a survey of the technologies that are protected through patent rights with conjugated antibodies (ADCs). For the mapping of technological information, the databases Derwent Innovations Index, LENS.ORG, Cortellis Competitive Intelligence and the National Institute of Industrial Property (INPI). Among the ten countries that most deposited patents are the United States with 416 patents, China (149) and Canada (92). Brazil has 11 patent deposits, but only one as a resident.
\end{abstract}

Keywords: Antibodies. Neoplasm. Patents.

Área Tecnológica: Biotecnologia. Saúde Pública. Propriedade Industrial. 


\section{Introdução}

Os anticorpos conjugados (antibody-drug conjugated-ADCs) têm como finalidade entregar de forma seletiva drogas bastante potentes citotoxicamente nas células doentes sem promover ou minimizando danos ao tecido saudável. O conceito de entrega seletiva de substâncias tóxicas para células-alvo que ocasionam doenças foi originalmente proposto em 1913 pelo alemão médico e cientista Paul Ehrlich (1913), mas somente 45 anos mais tarde, tal conceito designado como terapia direcionada foi demonstrado, pela primeira vez, quando o metotrexato foi conjugado a um anticorpo direcionando a célula leucêmica (MATHE; LOC; BERNARD, 1958). No âmbito da saúde, o desenvolvimento de anticorpos conjugados vem sendo a nova ferramenta promissora para diversas doenças (ARLOTTA; OWEN, 2019), como câncer e as autoimunes como lúpus (LIAO et al., 2017), entre outras. Porém, a obtenção do sucesso dessa bioterapia requer um grande conhecimento tanto da biologia como da química envolvida no processo, pois sua construção tem complexidade significativa, que vai desde a seleção dos métodos mais apropriados para obtenção de ADC específico como as propriedades do ligante, o medicamento $e$ a escolha dos locais de ligação (lisinas, cisteínas intercadeias, Glicanos Fc).

O câncer é atualmente responsável por uma em cada seis mortes no mundo, segundo a Organização Mundial da Saúde (OMS). Em paralelo, avanços tecnológicos vêm sendo direcionados no combate a essa doença, que é um problema de saúde pública, caracterizada pela proliferação desordenada das células, as quais possuem a capacidade não apenas de se tornarem bastante agressivas, mas também de se espalharem para outras regiões do corpo (INCA, 2019). Dessa forma, a biotecnologia vem construindo, por meio da nanotecnologia, a criação de diversas metodologias na busca de produtos direcionados contra o câncer, entre elas, a utilização de anticorpos conjugados com drogas (ADCs). A construção dos ADCs ocorre a partir de três componentes: um anticorpo monoclonal (monoclonal antibody - $m A b$ ) que é específico para um antígeno tumoral; um agente citotóxico altamente potente e a espécie ligante que permite a ligação covalente da citotoxina ao mAb por meio de uma proteína ou de um glicano (WAKANKAR et al., 2011).

Diante da perspectiva dos anticorpos conjugados (ADCs) ou imunoconjugados estarem se tornando uma classe bastante importante como agentes terapêuticos na investigação clínica para o tratamento do câncer (SENTER, 2009), é fundamental buscar informações, fomentar e monitorar as produções tecnológicas contidas nas patentes sobre o tema.

Nessa linha, Santos et al. (2004) destacam uma grande variedade de métodos de prospecção, como a inteligência competitiva e o mapeamento tecnológico, que são fontes para criar processos sistemáticos de análise de tecnologias (principalmente quando emergentes), suas características, rotas de desenvolvimento e impactos potenciais no futuro.

O monitoramento e a proteção da propriedade intelectual, por meio de documentos de patentes, das novas tecnologias é de extrema importância. Por isso, as empresas devem acompanhar atentamente as inovações tecnológicas de interesse, quando o cenário é caracterizado pelo lançamento crescente de novos produtos (OLIVEIRA et al., 2019 apud HERTZ; PARIKKA, 2012). Assim, o presente trabalho teve como objetivo realizar um levantamento das tecnologias que estão protegidas por meio dos direitos de patentes relacionadas com anticorpos conjugados (ADCs). 


\section{Metodologia}

Na coleta dos dados para o mapeamento da informação tecnológica foram utilizadas as bases de dados: Derwent Innovations Index (Thomson Reuters), LENS.ORG, que é uma Plataforma de Cartografia Aberta, e a base de dados do Instituto Nacional de Propriedade Industrial (INPI), a fim de verificar as patentes residentes com anticorpos conjugados. A partir dessas fontes de informação foram sistematizados os indicadores: panorama temporal de depósitos de patentes, perfil dos depósitos de patentes (origem e titularidade), as patentes dos residentes, área tecnológica, tipos de patentes e as indicações encontradas nos documentos de patentes com anticorpos conjugados.

A pesquisa e a coleta das informações tecnológicas nas bases de dados de patentes foram realizadas entre os meses de maio e junho de 2019. Os dados das patentes recuperadas na base Derwent Innovations Index foram tratados e analisados por meio do software VantagePoint ${ }^{\circledR}$, permitindo a exploração e o tratamento de grande quantidade de informação tecnológica. Nesse software, os documentos são tratados com técnicas bibliométricas avançadas, permitindo a visualização dos dados sob diversas formas por meio do agrupamento de países, de inventores, de instituições, de titulares, entre outros (VantagePoint ${ }^{\circledR}, 2012$ ).

Outra ferramenta importante e que foi utilizada para obter informações contidas nas patentes foi o Clarivate Analytics Cortellis ou Inteligência Competitiva da Cortellis. Os dados das patentes foram compilados usando o Derwent World Patent Index (DWPI), que coleta informações sobre mais de 71 milhões de patentes de 50 autoridades em todo o mundo e os organiza em famílias de patentes. Como as patentes são direitos regionais, muitos documentos podem ser publicados para a mesma invenção; reunindo-os em famílias facilita contar o número de invenções em vez de patentes individuais, o que evita a contagem dupla e fornece uma base uniforme para comparar os resultados (CLARIVATE ANALYTICS, 2017).

A estratégia de busca utilizada consistiu na entrada de palavra-chave no campo Tópico para obter o termo "conjugat* antibod*" para a base de dados Derwent (703 registros) (Tabela 1). Na base de dados Lens, a busca foi realizada nos campos Title/Abstract/Claims. Nessa base de dados, foi utilizado um refinamento na busca, que foi para os tipos de documentos "patentes depositadas" e "patentes concedidas". Foram encontrados no total 403 documentos e 171 families, observou-se que apenas 54 patentes foram concedidas e 351 patentes com solicitação pendente ou em andamento. Para a busca no INPI, utilizou-se a palavra-chave no campo Resumo. Optou-se por não restringir totalmente os campos por ano e por Classificação Internacional de Patentes, por exemplo. 


\section{Resultados e Discussão}

A Tabela 1 apresenta o número de documentos recuperados nas bases de dados para as tecnologias protegidas por direito de patente usando a palavra-chave definida na metodologia.

Tabela 1 - Número de patentes encontradas nos bancos de dados

\begin{tabular}{cccc}
\hline Panco de Dados & LENS Patent & INPI \\
$\begin{array}{c}\text { "conjugat* antibod*" } \\
\text { (conjugat* AND antibod*) }\end{array}$ & 703 & $\begin{array}{c}403 \\
(171 \text { familias })\end{array}$ & 11 \\
\hline
\end{tabular}

Fonte: Elaborada pelas autoras deste artigo (2019)

Na Figura 1, observa-se que, desde 1974, existem pedidos de patente relacionado a anticorpos conjugados. A partir da década de 1995, percebeu-se o maior número de depósito de patentes, que pode estar relacionado a investimentos em Pesquisa e Desenvolvimento nos últimos anos (BRASIL, 2018). A patente depositada na Alemanha em 1974 trata-se da "Purification of protein conjugates by preparative electrophoresis esp. to isolate fluorescein conjugated antibody contg. Gamma globulin fractions" (Número da Patente: DE 2431719) e de titularidade da BEHRINGWERKE AG, que, atualmente, é o Parque Industrial de Behringwerke Marburg, um centro de biotecnologia com empresas farmacêuticas inovadoras.

A evolução no crescimento na quantidade de patentes depositadas a partir de 1997 é notória, sendo tal crescimento representativo no ano 2015 com 93 depósitos e em 2018 com 96 depósitos. Cabe ressaltar que o intervalo entre 2018 a 2019, o número de documentos pode aumentar devido às patentes que estão em período de sigilo de 18 meses, fase obrigatória em todo processo de proteção do invento.

Figura 1 - Evolução temporal sobre o número de patentes com o termo "conjugat* AND antibod*"

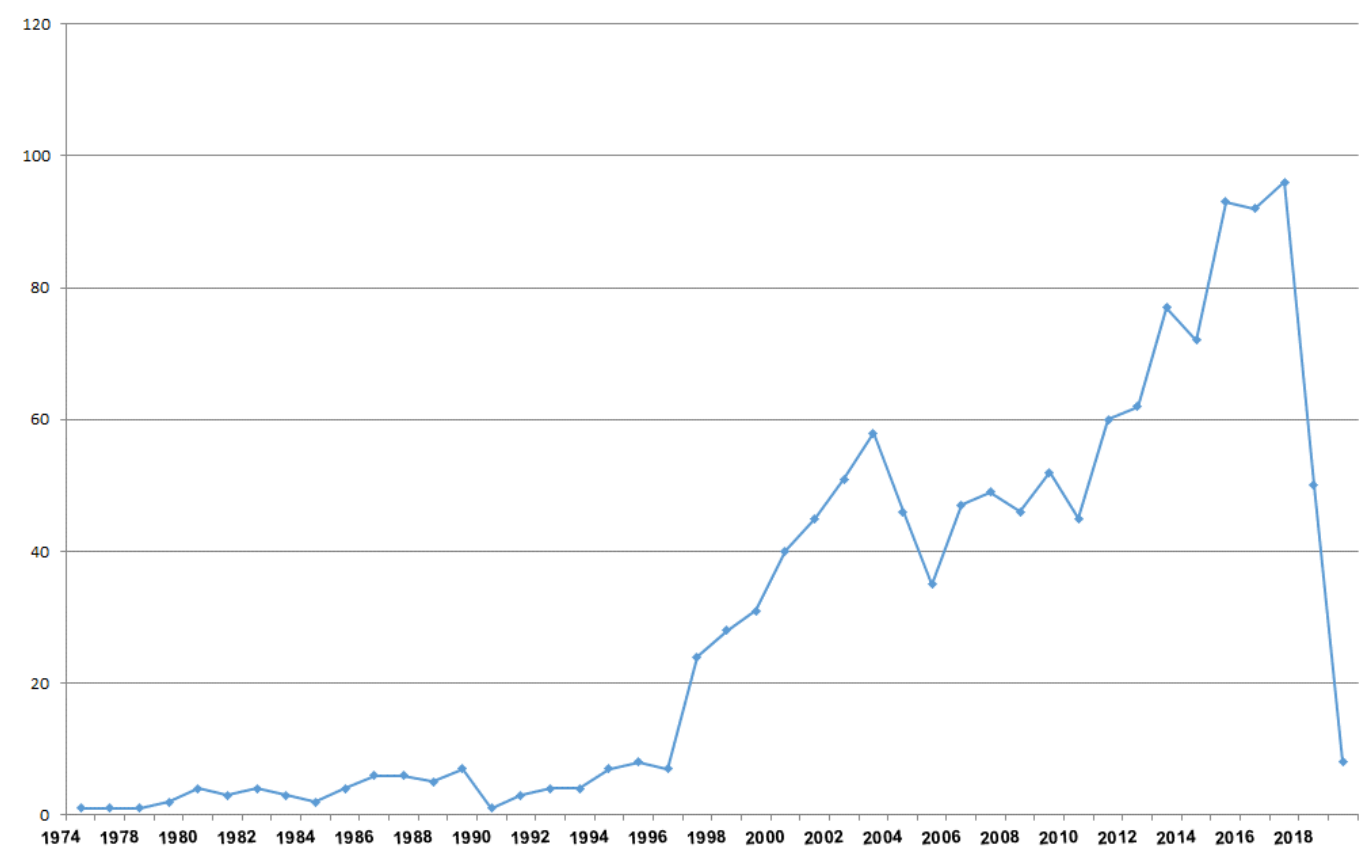

Fonte: Elaborada pelas autoras deste artigo (2019) 
A Figura 2 apresenta os dez primeiros países que mais depositaram patentes com anticorpos conjugados. O país que mais se destaca com o desenvolvimento e proteção dos inventos são os Estados Unidos com 416 patentes, isso pode estar relacionado ao maior número de investimentos, principalmente da indústria de biotecnologia em Pesquisa e Desenvolvimento (P\&D) para a produção novos fármacos. Em seguida, a China (149), que, somente em 2018, realizou 15 depósitos de patentes relacionados a anticorpos conjugados. Uma indústria farmacêutica da China (Innovent Biologics) arrecadou US\$ 485 milhões em 2018 por ampliar seu portfólio de medicamentos oncológicos, entre o principal o sintilimab, anticorpos para tratar o linfoma de Hodgkin (MORRISON, LAHTEENMAKI; 2019). Esta indústria chinesa desenvolve, fabrica e comercializa medicamentos inovadores para tratamento de doenças crônicas, como o câncer.

Muitas outras indústrias, em especial as americanas, no ramo da biotecnologia foram responsáveis em obter maior número de aprovações da Food and Drug Administration (FDA) para novos medicamentos (MORRISON; LAHTEENMAKI, 2019). De acordo com Morrison e Lahteenmaki (2019), a maior Oferta Pública Global (IPO sigla em inglês) em um único ano se deu de empresas biotecnológicas com aquisições para a terapia celular, terapia genética viral e de anticorpos.

Para o âmbito nacional, o Brasil contabiliza 11 depósitos de patentes no banco de dados do INPI. No entanto, apenas um documento de patente é de titularidade de entidade brasileira (Tabela 2). A patente residente (PI1003755-1) trata-se de um invento de imunocomplexo de antígeno-conjugado, ou melhor, um método para detecção precoce de anticorpos IgM em pacientes infectados com vírus da Dengue. Com a data de depósito em 7 de maio de 2010, consta até a data de outubro de 2018 o código de publicação 7.1 que é um parecer técnico em desacordo com os artigos 24 e 25 da Lei n. 9.279/1996, Lei de Propriedade Industrial.

Uma das primeiras patentes depositadas no Brasil via Patent Cooperation Treaty (PCT) é de 1996 da Connaught Laboratories Limited do Canadá. Após aliança com o Instituto Pasteur, a Connaught Laboratories Limited passa a designar como Sanofi Pasteur. É importante destacar que as siglas WO (World Intellectual Property Organization) e EP (Patent Office of Europe) não são países e sim escritórios regionais que prestam serviços de propriedade intelectual, como a recepção dos depósitos de patentes. A Tabela 2 não descreve todos os países em que a patente foi depositada, mas os depósitos nacionais e suas origens. Ela sinaliza que a maior parte das patentes depositadas no Brasil para a tecnologia avaliada não possui origem nacional. 
Figura 2 - Os 10 primeiros países e escritórios de patentes que mais depositaram patentes relacionadas a anticorpos conjugados

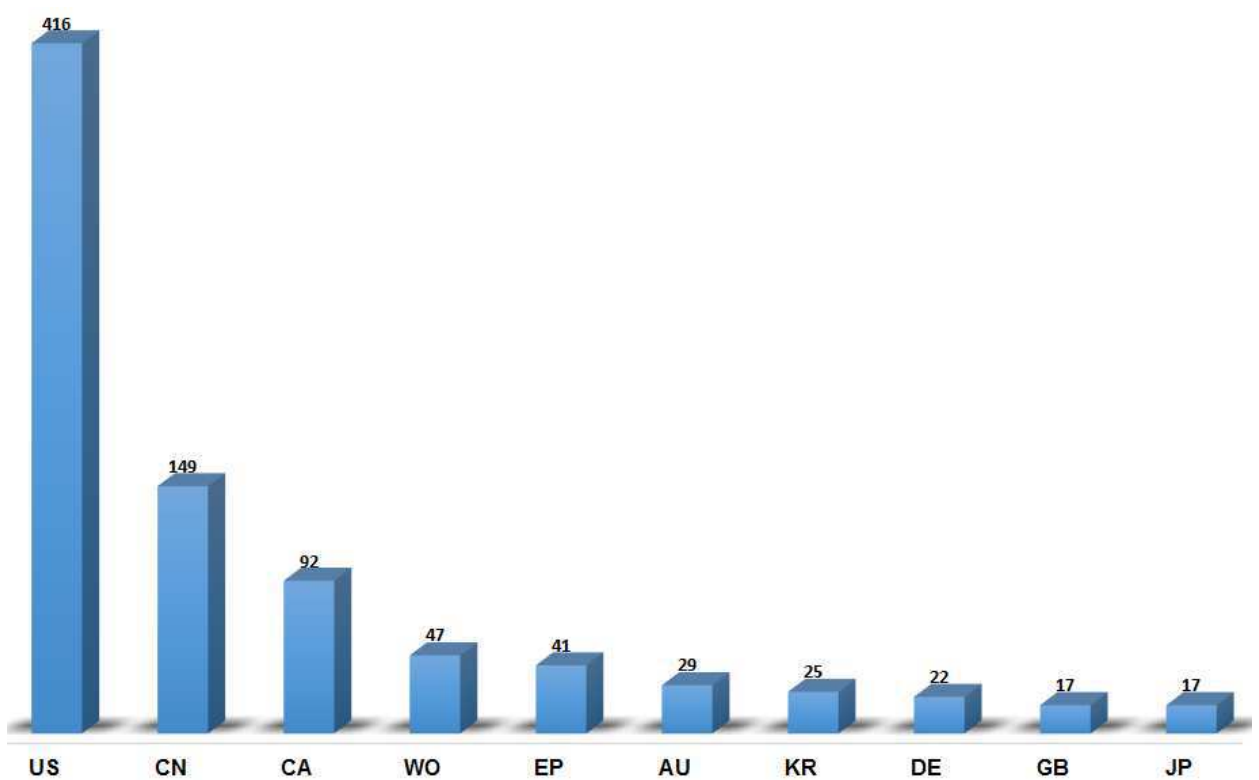

Legenda: US - Estados Unidos; CN - China; CA - Canada; WO - Organização Mundial de Propriedade Intelectual; EP - Escritório de Patentes da Europa; Au Austrália; KR - Coréia; DE - Alemanha; GB - Reino Unido; JP - Japão.

Fonte: Elaborada pelas autoras deste artigo (2019)

Os documentos analisados mostram que as indústrias lideram o ranking em depósitos de patentes (Figura 3), observando também patentes de empresas, institutos de pesquisa e universidades. De acordo com os dados, os Estados Unidos (US), a China (CN) e o Canadá (CA) são os que apresentaram nas quatro categorias o maior número de patentes nos quatros segmentos. As tecnologias patenteadas nos institutos de pesquisas da Alemanha obtiveram um número de patente um pouco acentuado (13) com relação aos outros setores apontados.

Figura 3 - Perfil dos depositantes por países: Top 10

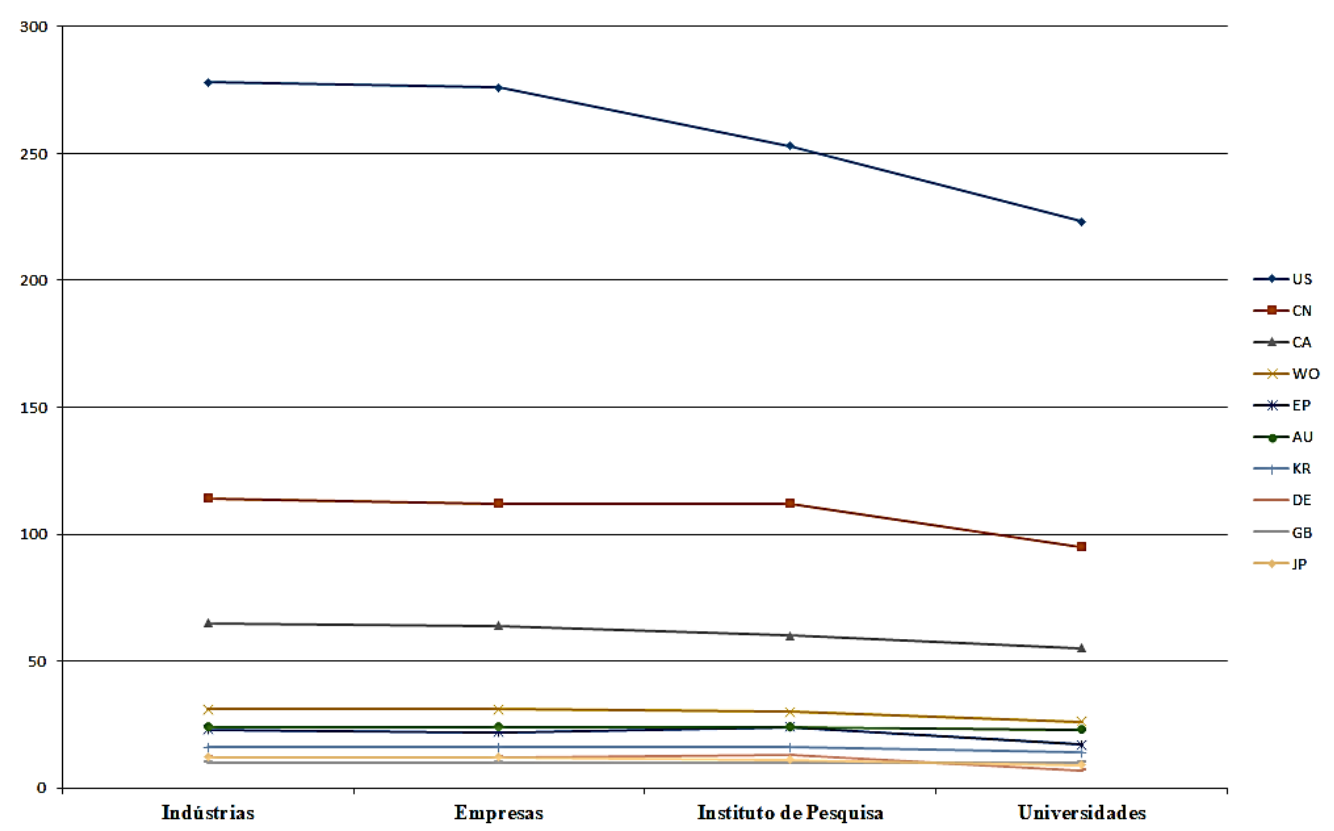

Legenda: US - Estados Unidos; CN - China; CA - Canada; WO - Organização Mundial de Propriedade Intelectual; EP - Escritório de Patentes da Europa; Au Austrália; KR - Coréia; DE - Alemanha; GB - Reino Unido; JP - Japão.

Fonte: Elaborada pelas autoras deste artigo (2019) 
Na publicação do Ministério da Ciência, Tecnologia e Inovação (BRASIL, 2018), destaca-se que as principais economias do mundo investem fortemente em pesquisa e desenvolvimento $e$ que nos países líderes em desenvolvimento tecnológico, por exemplo, os citados nas Figuras 2 e 3, as empresas investem mais do que o governo nessas atividades. Em países como Estados Unidos, China, Coreia e Japão, as empresas são responsáveis por mais de $70 \%$ dos dispêndios nacionais de pesquisa e desenvolvimento (BRASIL, 2018).

A Tabela 2 mostra que a empresa Genentech Inc., membro do Grupo Roche, apresenta interesse no mercado brasileiro, colocando-o na lista de países prioritários para proteção da tecnologia. A Genentech é uma empresa americana líder em biotecnologia que apresenta como portfólio Pesquisa, Desenvolvimento e Inovação (PD\&I) de medicamentos para doenças crônicas. Outro destaque é a Immunomedics (identificada por IX na Tabela 2), que depositou patente via PCT em 2004 e com data de expiração em 16 de junho de 2023 (WO-2004058298). Esta se apresenta como patente de novo uso e desenvolve medicamento para o tratamento de Leucemia linfoblástica aguda; Doença autoimune; Linfoma de células B; Leucemia linfocítica crônica; Macroglobulinemia; Mieloma múltiplo; Micose fungóide; Linfoma não-Hodgkin; Linfoma de células $\mathrm{T}$.

Tabela 2 - Patentes depositadas no Brasil por titularidade, país e ano

\begin{tabular}{|c|c|c|c|c|}
\hline & Título & TitulaRES & PAís & Ano \\
\hline I & $\begin{array}{l}\text {-Farmacêuticas, métodos para tratar câncer, } \\
\text { método de produção de um composto } \\
\text { conjugado e conjugado de anticorpo-droga. }\end{array}$ & Genentech Inc. & Estados Unidos & 2019 \\
\hline II & $\begin{array}{l}\text {-Composto conjugado anticorpo-droga, composição } \\
\text { farmacêutica, método para tratar câncer e kit. }\end{array}$ & Genentech Inc. & Estados Unidos & 2014 \\
\hline III & $\begin{array}{l}\text {-Farmacêutica, método de tratamento do } \\
\text { câncer, kit para o tratamento do câncer, } \\
\text { intermediário ligante-droga, porção e } \\
\text { composto de porção droga de dímero CBI. }\end{array}$ & Genentech Inc. & Estados Unidos & 2014 \\
\hline IV & $\begin{array}{l}\text {-Conjugado anticorpo-droga modificado } \\
\text { compreendendo uma droga ligada ao anticorpo } \\
\text { modificado e seu método de produção. }\end{array}$ & Alteogen Inc. & $\begin{array}{l}\text { República } \\
\text { da Coreia }\end{array}$ & 2013 \\
\hline $\mathrm{V}$ & $\begin{array}{l}\text {-Método para rápida detecção e identificação } \\
\text { de um ou mais micro-organismos alvos vivos } \\
\text { em uma amostra; dispositivo para rápida } \\
\text { detecção e identificação de um ou mais micro- } \\
\text { organismos alvos vivos em uma amostra; e } \\
\text { teste de kit para rápida detecção e identificação } \\
\text { de um ou mais micro-organismos alvos vivos } \\
\text { em uma amostra para uso no método. }\end{array}$ & Nanologix Inc. & Estados Unidos & 2012 \\
\hline VI & $\begin{array}{l}\text {-Produção de um anticorpo, conjugado de } \\
\text { anticorpo, formulação farmacêutica, uso do } \\
\text { anticorpo, métodos de tratamento, de indução } \\
\text { e de diagnóstico de doença em um indivíduo. }\end{array}$ & $\begin{array}{l}\text { Roche Glycart AG } \\
(\mathrm{CH}) \text { da Suíça }\end{array}$ & $\begin{array}{l}\text { Organização } \\
\text { Europeia de } \\
\text { Patentes }\end{array}$ & 2011 \\
\hline VII & $\begin{array}{l}\text {-Imunocomplexo (antígeno-anticorpo), } \\
\text { conjugado a peroxidasse para detecção de } \\
\text { anticorpos IGM para o vírus da dengue. }\end{array}$ & $\begin{array}{l}\text { Instituto Evandro } \\
\text { Chagas }\end{array}$ & Brasil & 2010 \\
\hline VIII & $\begin{array}{l}\text {-Composição farmacêutica, método de diagnóstico } \\
\text { ou monitoramento de doença, usos de agente, de } \\
\text { anticorpo e de células t citolíticas ou que liberam } \\
\text { citosina, agente, anticorpo, conjugado e kit. }\end{array}$ & $\begin{array}{l}\text { Ganymed } \\
\text { Pharmaceuticals } \\
\text { AG da Alemanha }\end{array}$ & $\begin{array}{l}\text { Organização } \\
\text { Europeia de } \\
\text { Patentes }\end{array}$ & 2006 \\
\hline
\end{tabular}




\begin{tabular}{|c|c|c|c|c|}
\hline IX & $\begin{array}{c}\text {-Imunoterapia de malignidades de células } \\
\text { B e doenças autoimunes usando anticorpos } \\
\text { não conjugados e conjugados, combinações } \\
\text { de anticorpos e proteínas de fusão. }\end{array}$ & Immunomedics, Inc. & Estados Unidos & 2003 \\
\hline $\mathrm{X}$ & $\begin{array}{l}\text {-Anticorpo, conjugado, sequência de } \\
\text { polinucleotídeos, vetor, célula hospedeira, } \\
\text { hibridoma, composição farmacêutica, } \\
\text { processos para fabricar um anticorpo ou um } \\
\text { conjugado, e, para tratar um humano ou } \\
\text { animal em necessidade deste tratamento. }\end{array}$ & Zeneca Limited (GB) & Reino Unido & 1997 \\
\hline XI & $\begin{array}{l}\text {-Anticorpos quiméricos para administração de } \\
\text { antígenos a células selecionadas do sistema imune. }\end{array}$ & $\begin{array}{l}\text { Connaught } \\
\text { Laboratories } \\
\text { Limited (CA) }\end{array}$ & Estados Unidos & 1996 \\
\hline
\end{tabular}

Fonte: Elaborada pelas autoras deste artigo a partir da Base de dados INPI (2019)

Os maiores depositantes de patentes com o termo anticorpos conjugados identificados são empresas e indústrias (Figura 4). A empresa que aparece com o maior número de depósitos é a Genentech Inc. (247), seguida pela Immunomedics Inc. (125). Quanto às universidades que desenvolvem pesquisas com anticorpos conjugados e se protegem por meio de direitos de patentes, a do Texas (44), a da Califórnia (29) e a de Columbia (32) se destacam com um número significativo de depósitos.

Figura 4 - Lista as palavras em nuvem dos detentores de patentes no mundo envolvendo anticorpos conjugados

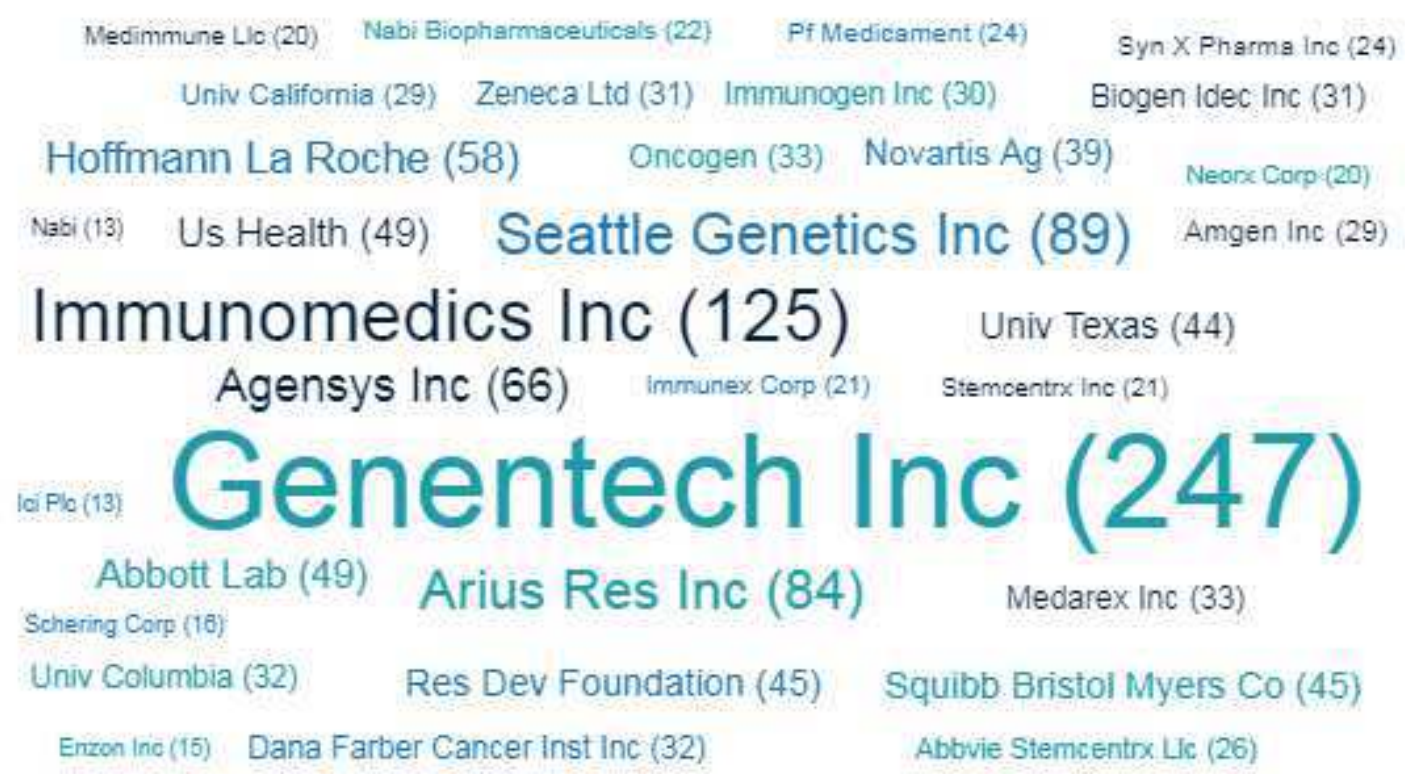

Fonte: Elaborada pelas autoras deste artigo a partir da Base de dados LENS (2019)

Na Figura 5 observa-se a matriz de Classificação Internacional de Patentes quando se cruzam os dados com os 10 primeiros titulares das patentes, permitindo, assim, analisar a ligação deles com o setor tecnológico. A CIP está representada pelo nó azul e os titulares com o nó amarelo. A quantidade de patente de cada depositante é representada pela largura da linha de ligação. Como demonstrada na matriz de ocorrências, a CIP com maior destaque está representada na seção A, que corresponde a necessidades humanas. A classificação com subclasse A61k (marcado 
em vermelho) representa preparações para finalidades médicas, odontológicas ou higiênicas, foi a que teve maior registro com o total de 299 repetições. Pôde-se observar que o grupo A61K 039 - Preparações medicinais contendo antígenos ou anticorpos e o subgrupo A61k 039/395 Haptenos ou antígenos ligados a carreadores foi o que mais apareceu nos documentos. Ainda, a prospecção tecnológica apresentou a classificação G01N - 033/53, que engloba a investigação ou a análise dos materiais pela determinação de suas propriedades químicas ou físicas; imune ensaio; ensaios envolvendo ligantes bioespecíficos; materiais para eles.

Figura 5 - Matrix de ocorrência da Classificação Internacional de Patentes por titulares

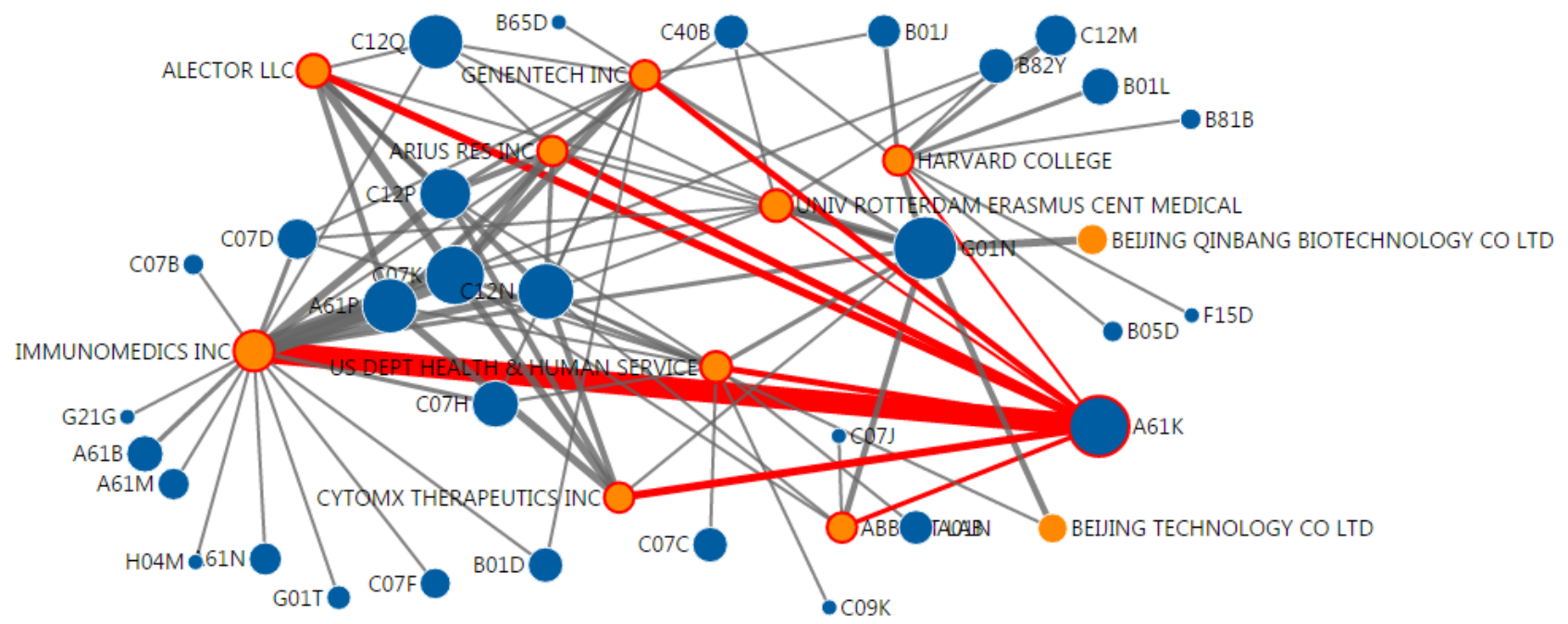

Fonte: Elaborada pelas autoras deste artigo usando o VantagePoint @ (2019)

As indústrias Immunomedics Inc. e Genentech Inc. obtiveram, também, na Classificação Internacional a subclasse $\mathrm{C} 12 \mathrm{~N}$ (Micro-organismos ou enzimas, suas composições) com subgrupo C12N 15/09 que corresponde à tecnologia do DNA recombinante. E cerca de 124 ocorrências no subgrupo imunoglobulina, por exemplo, anticorpo mono ou policlonais (C07K 016/18).

Ao verificar os principais tipos de inventos contidos nas patentes depositadas com o termo anticorpos conjugados (Figura 6), a maior parte dos documentos de patentes está direcionada à proteção da invenção de uma formulação. O tipo de patente destinado a diagnóstico, análise e ensaios são representados como a segunda solicitação mais procurada para proteção de um invento. De acordo com Abreu (2017), os titulares de patentes utilizam de estratégias para prolongar o prazo de exclusividade sobre as tecnologias. As patentes, em muitos casos, combinam categorias de produto e processo e tais modalidades de patentes acompanham os desdobramentos das etapas do processo de inovação de novos medicamentos. $\mathrm{O}$ autor cita, ainda, que os novos usos no setor farmacêutico estão associados às aplicações de um produto já descrito como útil na medicina. 
Figura 6 - Os tipos de patentes depositadas com o termo anticorpos conjugados

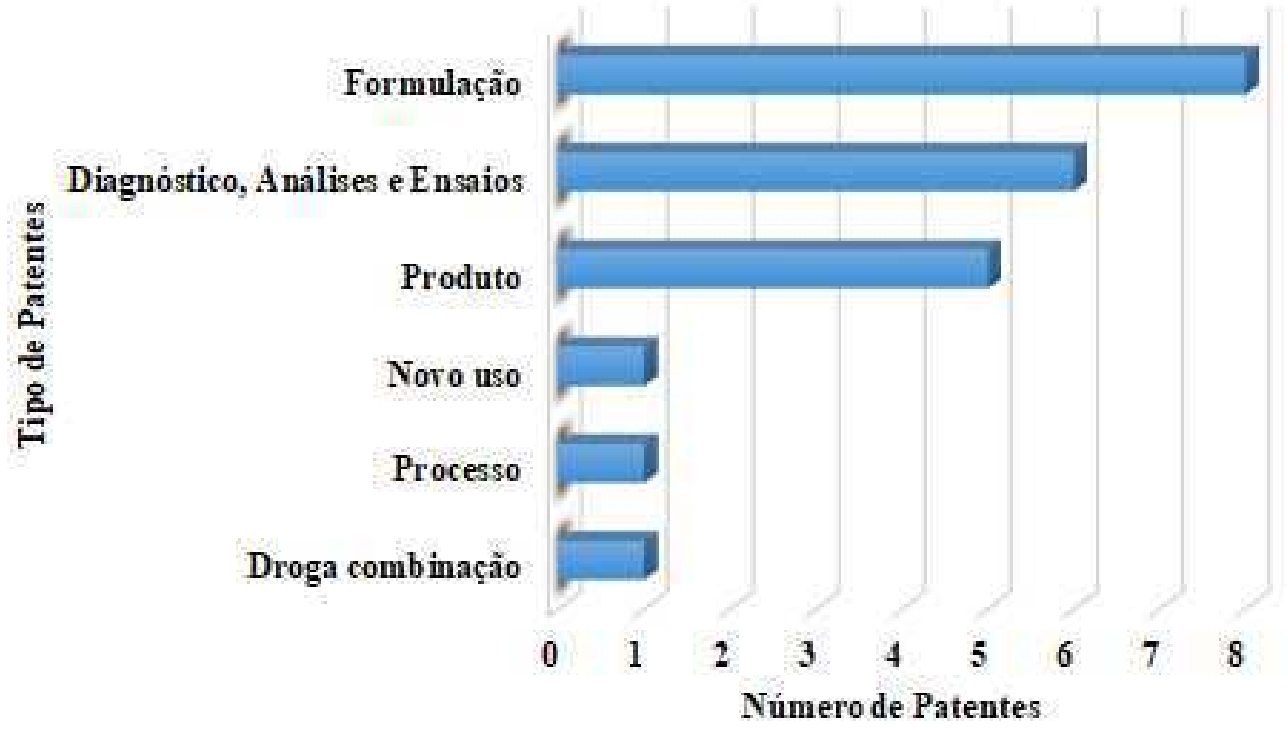

Fonte: Elaborada pelas autoras deste artigo a partir da ferramenta Inteligência Competitiva da Cortellis (2019)

O Acordo sobre Aspectos dos Direitos de Propriedade Intelectual relacionados ao Comércio (Acordo TRIPS) estabelece, em seu artigo 27, que qualquer invenção, de produto ou de processo, em todos os setores tecnológicos, será patenteável, desde que seja nova, apresente ato inventivo e tenha aplicação industrial. No entanto, deixa a critério dos países-membros a interpretação desses requisitos de patenteabilidade (BRASIL, 2013).

A Comunidade Europeia prevê a patenteabilidade de substâncias para "uso terapêutico", mesmo se as substâncias em questão já são conhecidas no estado da técnica. No entanto, para se patentear um anticorpo, as reivindicações devem ressaltar a especificidade do anticorpo para um dado alvo, e se o alvo para o qual o anticorpo é direcionado foi descrito no estado da técnica ou não (GERMINARIO et al., 2018).

Jannuzzi et al. (2008) destacam que as invenções relacionadas a substâncias ou composições, que visam a proteger o uso no tratamento de determinadas doenças, podem ser de novo uso, como medicamento, produto já conhecido com utilização fora do âmbito medicinal, dito primeiro uso médico. No Brasil, a denominação "primeiro uso médico" de um produto conhecido não é permitida por não atender ao requisito de novidade (JANNUZZI; VASCONCELLOS; SOUZA, 2008).

No entanto, no documento da Câmara dos Deputados, que trata da revisão da lei de patentes (BRASIL, 2013), coloca-se as patentes que buscam a proteção de um novo uso médico ou terapêutico, de um composto já conhecido no campo médico, enquadradas nas seguintes categorias:

- Nova aplicação terapêutica para um medicamento já registrado.

- Nova aplicação terapêutica de um composto em formulação, apresentação e dosagens diferentes daquelas do medicamento registrado.

- Nova aplicação terapêutica de compostos com atividade biológica conhecida, mas que não chegaram ao mercado ou não foram considerados promissores para a primeira indicação terapêutica. 
Germinario et al. (2018) citam que os anticorpos são utilizados em várias tecnologias, em particular, em diagnóstico (ensaios imunoenzimáticos), detecção de marcadores específicos para câncer e outros para diagnosticar tumores; infecções bacterianas ou distúrbios hormonais, avaliações de imuno-hispatologia do câncer, entre outros. Na combinação de drogas, os anticorpos podem ser usados como transportadores de drogas para alvos específicos; conjugados com toxinas para formar imunotoxinas para câncer e terapia viral, ou com enzimas para converter um pró-fármaco em uma droga (GERMINARIO et al., 2018).

Em se tratando da indicação utilizada no processo de patenteabilidade da invenção com o termo anticorpos conjugados podem ser observados na Figura 7, que na maioria das indicações encontradas nas patentes são para tratamento de câncer. $O$ termo câncer se refere ou descreve a uma condição fisiológica que é normalmente caracterizada pelo crescimento/proliferação celular não regulada. Um tumor compreende uma ou mais células cancerosas. Os exemplos de câncer incluem os linfomas, blastomas, sarcoma e leucemia ou enfermidades linfoides malignas, entre outros (BR 112018006016-0 A2). Foram encontradas nas patentes as indicações para o tratamento para doenças autoimunes e para o HIV. Cabe ressaltar que foram listadas as 10 primeiras indicações para a utilização da invenção patenteada com anticorpo conjugado.

Nesse contexto, Germinario et al. (2018) ressaltam que os anticorpos têm ganhado interesse devido a sua capacidade de uso para tratar doenças autoimune, câncer e deficiências imunológicas e também como um meio de interferir com os complicados mecanismos de estimulação ou repressão da resposta imune do corpo e como portadores de estratégias de entrega de drogas e de direcionamento de drogas.

Figura 7 - Indicações encontradas nos documentos de patentes: Top 10

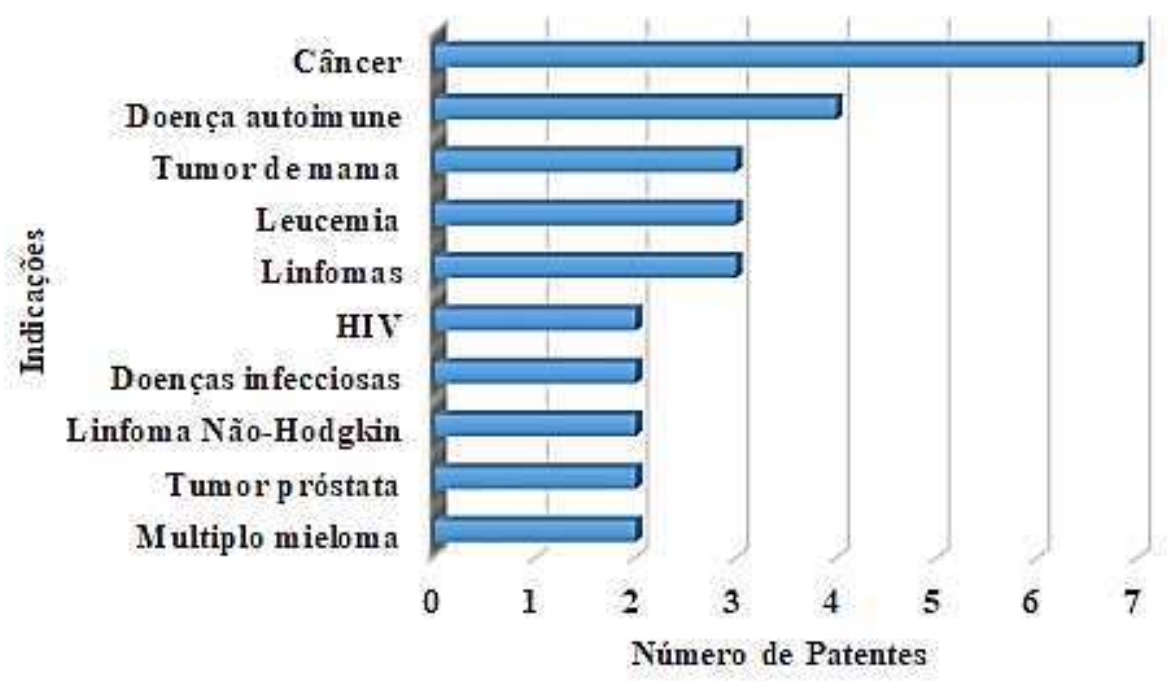

Fonte: Elaborada pelas autoras deste artigo a partir da ferramenta Inteligência Competitiva da Cortellis (2019)

É notório que o processo de desenvolvimento de novos fármacos é longo e custoso e, para a indústria farmacêutica que investe milhões em toda a estrutura de levar o produto ao mercado, é comum observar a redução de preços com o lançamento de um genérico (INTERFARMA, 2012). A expiração da patente dos medicamentos existentes permite a entrada de produtos substitutos no mercado, isso leva a uma descontinuidade da vantagem competitiva das empresas 
inovadoras (JANNUZZI; VASCONCELLOS; SOUZA, 2008). A expiração da patente provoca a redução do lucro das empresas líderes em razão do preço de tais produtos ser reduzido em cerca de $40 \%$, pela competição gerada pela oferta de medicamentos genéricos (ABREU, 2017).

Por exemplo, a patente (WO-02088172) de titularidade da BioPharma Inc., Seattle Genetics Inc., que cita a droga Brentuximab vedotin (Tabela 3), destinada ao tratamento de linfoma não Hodgkin e linfoma sistemático anaplásico de células grandes, apresenta o ano de expiração para 2027 (Figura 8). Nos ensaios clínicos com essa droga, englobam-se numerosas combinações diferentes com outras drogas, incluindo anticorpos moduladores do sistema imunológico, anticorpos antiagiogênicos, inibidores de pequenas moléculas direcionados a quimioterapias citotóxicas como drogas individuais ou em combinação (CARTER; LAZAR, 2018).

Do ponto de vista estratégico, a droga Brentuximab vedotin apresenta desenvolvimento tecnológico para as seguintes aplicações: anticorpo conjugado, anticorpo conjugado monoclonal, anticorpo clínico, Imunoglobulina-G, formulação intravenosa, Infusão, Liofilização, formulação em pó, terapêutico biológico (Tabela 3). E apesar de ser o primeiro medicamento aprovado para o linfoma de Hodgkin refratário desde de 1977, em 2017, a Seattle Genetics Inc. anunciou que a Food and Drug Administration (FDA) aprovou o ADCETRIS (Brentuximab vedotin) para o tratamento de pacientes adultos com linfoma cutâneo anaplásico de células grandes (pcALCL) e micose fungoide (MF) expressando o CD30. O ALCL cutânea primária e MF são os subtipos mais comuns de linfoma cutâneo de células T. Esse tipo de linfoma é um câncer sanguíneo da pele sem cura conhecida e com poucas opções de tratamento.

Figura 8 - As principais patentes que citam as drogas relacionadas a anticorpos conjugados com as datas de expiração da patente

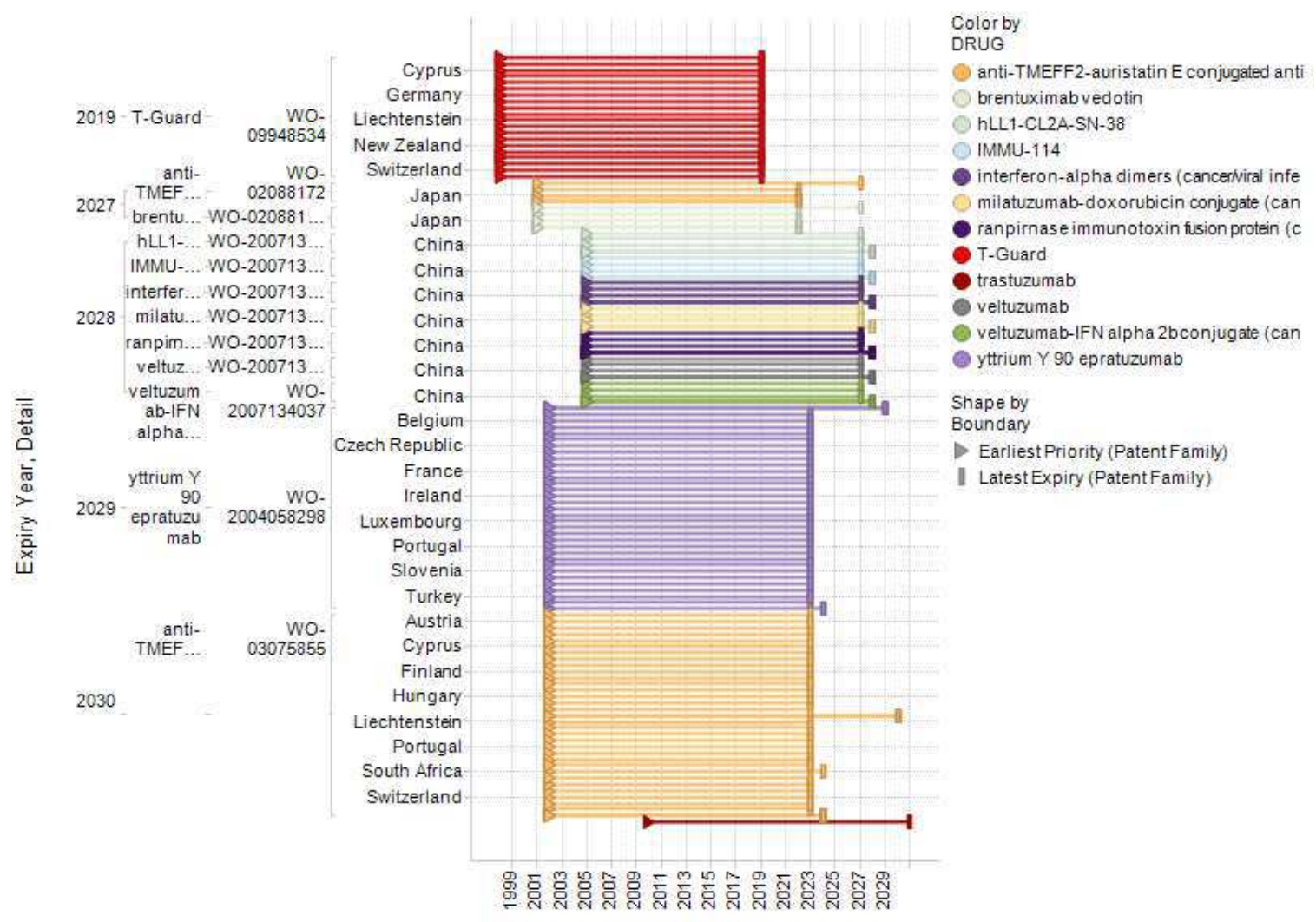

Year

Fonte: Elaborada pelas autoras deste artigo a partir da ferramenta Inteligência Competitiva da Cortellis (2019) 
A Figura 8 apresenta uma patente com vigência expirada de acordo com a lei. A patente W009948534 com título "methods and means for the treatment of immune related diseases", de titularidade da Immunotoko BV e da Universidade Radboud (localizada na Holanda), que descreveu a droga T-Guard, teve a primeira data de publicação em 29 de setembro de 1999 e o tempo de expiração foi em 19 de março de 2019. A invenção patenteada proporciona imunotoxinas compreendendo um anticorpo e uma substância tóxica em coquetéis de tais conjugados direcionados para diferentes alvos associados com uma população de células, em que um alvo é escolhido a partir do CD3 ou CD7. A combinação, preferencialmente, é um coquetel direcionado contra ambos.

Tabela 3 - Informações encontradas nas patentes relacionadas às doenças crônicas de acordo com os alvos

\begin{tabular}{|c|c|c|c|c|c|}
\hline $\begin{array}{l}\text { Número } \\
\text { Patente }\end{array}$ & Titulares & INDICAÇÃO & Alvos & Drogas & TIPO PATENTE \\
\hline $\begin{array}{c}\text { WO- } \\
2004058298\end{array}$ & $\begin{array}{l}\text { Immunomedics } \\
\text { Inc. }\end{array}$ & $\begin{array}{c}\text { Leucemia } \\
\text { linfoblástica aguda; } \\
\text { Doença autoimune; } \\
\text { Linfoma de células } \\
\text { B; Leucemia } \\
\text { linfocítica crônica; } \\
\text { Macroglobulinemia; } \\
\text { Mieloma múltiplo; } \\
\text { Linfoma não- } \\
\text { Hodgkin; Linfoma } \\
\text { de células T }\end{array}$ & $\begin{array}{c}\text { Inibidor da } \\
\text { molécula de } \\
\text { adesão celular } \\
\text { dos linfócitos B }\end{array}$ & $\begin{array}{c}\text { Yttrium Y } \\
\text { Epratuzumab }\end{array}$ & $\begin{array}{l}\text { Combinação } \\
\text { de drogas; } \\
\text { Novo uso }\end{array}$ \\
\hline $\begin{array}{c}\text { WO- } \\
2010078376\end{array}$ & $\begin{array}{l}\text { Ventana Medical } \\
\text { Systems Inc. }\end{array}$ & $\begin{array}{l}\text { Tumor de mama; } \\
\text { Doença de Hodgkin; } \\
\text { Tumor de faringe }\end{array}$ & $\begin{array}{l}\text { Modulador de } \\
\text { antígeno KI- } \\
\text { 67; Modulador } \\
\text { do receptor } \\
\text { de tirosina } \\
\text { quinasse } \\
\text { Erbb2; } \\
\text { Modulador } \\
\text { do receptor } \\
\text { progesterona; } \\
\text { Modulador de } \\
\text { CD20 antígeno } \\
\text { de linfócito B }\end{array}$ & & $\begin{array}{c}\text { Diagnóstico, } \\
\text { Análise e Ensaio; } \\
\text { Processo }\end{array}$ \\
\hline WO-09948534 & $\begin{array}{c}\text { Immunotoko } \\
\text { BV; Radboud } \\
\text { University }\end{array}$ & $\begin{array}{l}\text { Doença autoimune; } \\
\text { Infecção pelo } \\
\text { HIV-1; Desordem } \\
\text { imunológica; } \\
\text { Leucemia; } \\
\text { Linfoma; Rejeição } \\
\text { de transplante }\end{array}$ & & T-Guard & Formulação \\
\hline $\begin{array}{c}\text { WO- } \\
2019107962\end{array}$ & Ajou University & Câncer & $\begin{array}{l}\text { Inibidor do } \\
\text { receptor } \\
\text { de tirosina } \\
\text { quinasse } \\
\text { de Erbb2; } \\
\text { Antagonista } \\
\text { do receptor } \\
\text { do fator de } \\
\text { crescimento } \\
\text { epidérmico }\end{array}$ & $\begin{array}{l}\text { Cetuximab; } \\
\text { Trastuzumab }\end{array}$ & $\begin{array}{c}\text { Diagnóstico, } \\
\text { Análise e Ensaio; } \\
\text { Processo }\end{array}$ \\
\hline
\end{tabular}




\begin{tabular}{|c|c|c|c|c|c|}
\hline $\begin{array}{c}\text { WO- } \\
2017101863\end{array}$ & Kanda BioTech & $\begin{array}{l}\text { Câncer; Tumor } \\
\text { de mama }\end{array}$ & $\begin{array}{l}\text { Inibidor de } \\
\text { proteína-4 } \\
\text { de linfócito } \\
\text { T citotóxico; } \\
\text { Inibidor do } \\
\text { receptor } \\
\text { de tirosina } \\
\text { quinasse Erbb2 }\end{array}$ & $\begin{array}{l}\text { Ipilimumab; } \\
\text { trastuzumab } \\
\text { tremelimumab }\end{array}$ & $\begin{array}{l}\text { Diagnóstico, } \\
\text { Análise e Ensaio; } \\
\text { Formulação; } \\
\text { Produto } \\
\text {-Macromolécula }\end{array}$ \\
\hline $\begin{array}{c}\text { WO- } \\
2017059158\end{array}$ & $\begin{array}{l}\text { Bristol-Myers } \\
\text { Squibb Co }\end{array}$ & Câncer & $\begin{array}{c}\text { Estimulador de } \\
\text { transglutaminase; } \\
\text { imunoglobulina } \\
\text { G }\end{array}$ & & $\begin{array}{l}\text { Formulação; } \\
\text { Produto } \\
\text {-Macromolécula }\end{array}$ \\
\hline $\begin{array}{c}\text { WO- } \\
2015052537\end{array}$ & $\begin{array}{c}\text { Oxford } \\
\text { BioTherapeutics } \\
\text { Ltd. }\end{array}$ & $\begin{array}{l}\text { Câncer de bexiga; } \\
\text { Tumor de mama; } \\
\text { Câncer; Linfoma } \\
\text { difuso de grandes } \\
\text { células B; Tumor } \\
\text { do pâncreas }\end{array}$ & $\begin{array}{l}\text { Modulador do } \\
\text { receptor de } \\
\text { imunoglobulina } \\
\text { Fc; Inibidor } \\
\text { do antígeno } \\
\text { linfocitário } 75\end{array}$ & $\begin{array}{c}\text { DM4; } \\
\text { mertansine }\end{array}$ & $\begin{array}{l}\text { Formulação; } \\
\text { Produto } \\
\text {-Macromolécula }\end{array}$ \\
\hline $\begin{array}{c}\text { WO- } \\
2014210376\end{array}$ & $\begin{array}{l}\text { Stanford } \\
\text { University }\end{array}$ & Doença infecciosa & & & $\begin{array}{l}\text { Diagnóstico, } \\
\text { Análise e Ensaio }\end{array}$ \\
\hline $\begin{array}{c}\text { WO- } \\
2014009426\end{array}$ & $\begin{array}{c}\text { Innate Pharma } \\
\text { SA; Paul Scherrer } \\
\text { Institut }\end{array}$ & Câncer & & & $\begin{array}{c}\text { Diagnóstico, } \\
\text { Análise e } \\
\text { Ensaio; Produto } \\
\text {-Macromolécula }\end{array}$ \\
\hline $\begin{array}{c}\text { WO- } \\
2013166110\end{array}$ & $\begin{array}{l}\text { Allied-Bristol Life } \\
\text { Sciences LLC; } \\
\text { Yale University }\end{array}$ & $\begin{array}{c}\text { Leucemia } \\
\text { mielogênica } \\
\text { aguda; Sarcoma de } \\
\text { Ewing; Doença de } \\
\text { Hodgkin; Leucemia; } \\
\text { Linfoma; Melanoma; } \\
\text { Mieloma múltiplo; } \\
\text { Neuroblastoma; } \\
\text { Linfoma não- } \\
\text { Hodgkin; Tumor } \\
\text { de próstata }\end{array}$ & TLR agonistas & & Formulação \\
\hline $\begin{array}{c}\text { WO- } \\
2007134037\end{array}$ & $\begin{array}{c}\text { IBC } \\
\text { Pharmaceuticals } \\
\text { Inc; } \\
\text { Immunomedics } \\
\text { Inc. }\end{array}$ & $\begin{array}{c}\text { Doença autoimune; } \\
\text { Câncer; Infecção } \\
\text { pelo HIV; Doença } \\
\text { infecciosa }\end{array}$ & $\begin{array}{c}\text { Ligando } \\
\text { interferon alfa } \\
\text { 2; Agonista de } \\
\text { imunoglobulina } \\
\text { G; Agonista } \\
\text { do receptor de } \\
\text { citosina não } \\
\text { especificado; } \\
\text { Inibidor } \\
\text { do ligando } \\
\text { eritropoietina; } \\
\text { Inibidor da } \\
\text { proteína gp120 } \\
\text { do HIV }\end{array}$ & $\begin{array}{l}\text { IMMU-114; } \\
\text { doxorubicin; } \\
\text { hLL1-CL2A- } \\
\text { SN-38; } \\
\text { interferon- } \\
\text { alpha dímeros } \\
\text { (câncer/ infeção } \\
\text { viral), IBC; } \\
\text { milatuzumab- } \\
\text { doxorubicin } \\
\text { conjugate } \\
\text { (câncer), } \\
\text { Immunomedics; } \\
\text { ranpirnase } \\
\text { immunotoxin } \\
\text { fusion protein } \\
\text { (câncer), } \\
\text { Immunomedics; } \\
\text { veltuzumab; } \\
\text { veltuzumab- } \\
\text { IFN alpha } \\
\text { 2b conjugate } \\
\text { (câncer), IBC/ } \\
\text { Immunomedics }\end{array}$ & Formulação \\
\hline
\end{tabular}




\begin{tabular}{|c|c|c|c|c|c|}
\hline WO-03075855 & $\begin{array}{c}\text { Abbott } \\
\text { Laboratories; Eos } \\
\text { Biotechnology } \\
\text { Inc.; PDL } \\
\text { BioPharma Inc. }\end{array}$ & Tumor de Próstata & $\begin{array}{l}\text { Tomoregulin } \\
2 \text { modulator }\end{array}$ & $\begin{array}{l}\text { Anti-TMEFF2- } \\
\text { auristatin E } \\
\text { conjugated } \\
\text { antibodies, } \\
\text { Protein Design } \\
\text { Labs }\end{array}$ & $\begin{array}{l}\text { Diagnóstico, } \\
\text { Análise e } \\
\text { Ensaio; Produto } \\
\text {-Macromolécula }\end{array}$ \\
\hline WO-02088172 & $\begin{array}{l}\text { PDL BioPharma } \\
\text { Inc.; Seattle } \\
\text { Genetics Inc }\end{array}$ & $\begin{array}{c}\text { Doença autoimune; } \\
\text { Leucemia; Linfoma; } \\
\text { Neoplasma; } \\
\text { Tumor sólido }\end{array}$ & & $\begin{array}{c}\text { Anti-TMEFF2- } \\
\text { auristatin E } \\
\text { conjugated } \\
\text { antibodies, } \\
\text { Protein } \\
\text { Design Labs; } \\
\text { brentuximab } \\
\text { vedotin }\end{array}$ & Produto \\
\hline $\begin{array}{c}\text { WO- } \\
2012003995\end{array}$ & Cormus Srl & $\begin{array}{l}\text { Doença de Alzheimer; } \\
\text { Asma; Câncer; } \\
\text { Infecção pelo HIV; } \\
\text { Infecção pelo vírus } \\
\text { da hepatite C; } \\
\text { Hipercolesterolêmica; } \\
\text { Obesidade; Infecção } \\
\text { pelo vírus sincicial } \\
\text { respiratório; } \\
\text { Infecção viral }\end{array}$ & $\begin{array}{l}\text { Erbb2 tyrosine } \\
\text { kinase receptor } \\
\text { inhibitor }\end{array}$ & Trastuzumab & Formulação \\
\hline
\end{tabular}

Fonte: Elaborada pelas autoras deste artigo a partir da ferramenta Inteligência Competitiva da Cortellis (2019)

\section{Considerações Finais}

O mapeamento tecnológico dos anticorpos conjugados (ADCs) demonstra um crescimento das pesquisas para a produção de medicamentos no tratamento de doenças crônicas, por exemplo, o câncer. Conforme dados apresentados, pode-se afirmar a relevância dos ADCs, no cenário mundial, com o aumento do número de depósitos de patentes. Com os resultados obtidos, constatou-se uma evolução no número de depósitos de patentes a partir de 1997 sendo tal crescimento representativo no ano 2015 com 93 depósitos e em 2018 com 96 depósitos. Esse resultado indica uma tendência crescente demostrando um grande interesse da indústria farmacêutica para a produção de medicamentos com os anticorpos conjugados (ADCs) que tem como finalidade entregar de forma seletiva drogas bastante potentes nas células doentes sem promover ou minimizando danos ao tecido saudável para o tratamento das doenças crônicas.

Os Estados Unidos lideram o ranking no interesse para a proteção dessas tecnologias por meio de direitos de patentes (416) e com o maior número de indústrias, empresas e institutos de pesquisas nesse seguimento, seguido pela China (149), que, somente em 2018, realizou 15 depósitos de patentes relacionados a anticorpos conjugados. A indústria farmacêutica chinesa (Innovent Biologics) arrecadou US\$ 485 milhões em 2018 por ampliar seu portfólio de medicamentos direcionados para tratamento do câncer. No contexto brasileiro, contabiliza-se 11 depósitos de patentes no banco de dados do Instituto Nacional da Propriedade Industrial (INPI). Porém, foi encontrado apenas um documento de patente de titularidade de uma entidade nacional, os demais depósitos são de empresas estrangeiras que visualizam o mercado do Brasil como potencial competidor. 
Conclui-se que as publicações tecnológicas por meio das patentes são indicadores importantes para a pesquisa, desenvolvimento e inovação e, por isso, espera-se que os resultados apresentados neste trabalho possam ser úteis demonstrando que o número de pesquisadores/ indústrias que desenvolve a inovação no Brasil ainda é pouco relevante.

\section{Agradecimentos}

Agradecemos ao Conselho Nacional de Desenvolvimento Científico e Tecnológico (CNPq).

\section{Referências}

ABREU, J. C. Prospecção Tecnológica Aplicada na Otimização da Concessão de Patentes no Brasil: estudo de caso em patentes de medicamentos imunossupressores. 2017. 342 f. Tese (Doutorado em Políticas Públicas, Estratégias e Desenvolvimento) - Universidade Federal do Rio de Janeiro, UFRJ, Rio de Janeiro, 2017.

ARLOTTA, K. J.; OWEN, S. C. Antibody and antibody derivatives as cancer therapeutics.

Wiley Interdisciplinary Reviews: Nanomedicine and Nanobiotechnology, e1556, 2019.

DOI:10.1002/wnan.1556.

BRASIL. Plano de ação para a promoção da inovação tecnológica: 2018-2022. Secretaria de Desenvolvimento Tecnológico e Inovação. Brasília, DF: Ministério da Ciência, Tecnologia, Inovações e Comunicações, 2018.

BRASIL. A revisão da Lei de patentes: inovação em prol da competitividade nacional. Relator: Newton Lima; equipe técnica: Pedro Paranaguá (coord.) [et al.]; consultores legislativos: César Costa Alves de Mattos, Fábio Luis Mendes, Mauricio Jorge Arcoverde de Freitas [recurso eletrônico]. Brasília, DF: Câmara dos Deputados, Edições Câmara, 2013.

CARTER, P. J.; LAZAR, G. A. Next generation antibody drugs: pursuit of the "high-hanging fruit". Nature Reviews Drug Discovery, [S.I.], 17, p. 197-223, 2018.

CLARIVATE ANALYTICS. The State of Innovation Report 2017: The relentless desire to advance. Clarivate Analytics, [S.l.], 2017. Disponível em: https://clarivate.com/. Acesso em: 2 jun. 2019.

DE 2431719. Purification of protein conjugates by preparative electrophoresis: esp. To isolate fluorescein - conjugated antibody contg. gamma globulin fractions. 1974.

GERMINARIO, C. et al. Patentability of antibodies for therapeutic use in Europe. Nature Biotechnology, [S.l.], v. 36, p. 402-405, 2018.

GENENTECH, INC. Intermediário de ligante-droga, compostos conjugados de anticorpodroga, composições farmacêuticas, métodos para tratar câncer, método de produção de um composto conjugado e conjugado de anticorpo-droga. BR 112018006016-0 A2, 30 set. 2016, 6 abr. 2017. Disponível em: https://gru.inpi.gov.br/pePI/servlet/ImagemDocumentoPdfController? Acesso em: 2 jun. 2019.

INCA - INSTITUTO NACIONAL DO CÂNCER. Estimativa 2016/2017: Incidência de Câncer no Brasil. [2019]. Disponível em: http://www.inca.gov.br/wcm/dncc/2015/dados-apresentados.pdf. Acesso em: 2 jun. 2019. 
INTERFARMA. Associação da Indústria Farmacêutica de Pesquisa. Entendendo os medicamentos biológicos. 2012. Disponível em: https://www.interfarma.org.br/public/files/biblioteca/34-biologicossite.pdf. Acesso em: 2. jun. 2019.

JANNUZZI, A. H. L.; VASCONCELLOS, A. G.; SOUZA, C. G. Especificidades do patenteamento no setor farmacêutico: modalidades e aspectos da proteção intelectual. Cad. Saúde Pública, Rio de Janeiro, v. 24, n. 6, p. 1.205-1.218, jun, 2008.

JEFFERSON, O. A. et al. Mapping the global influence of published research on industry and innovation. Nature Biotechnology, [S.l.], v. 36, n. 1, 2018.

LIAO, X. et al. Renal-infiltrating CD11c+ cells are pathogenic in murine lupus nephritis through promoting CD4+ T cell responses. Clinical \& Experimental Immunology, [S.l.], v. 190, n. 2, p. 187-200, 2017. DOI:10.1111/cei.13017.

MATHE, G.; LOC, T. B.; BERNARD J. Effect on mouse leukemia 1210 of a combination by diazoreaction of amethopterin and gamma globulins from hamsters inoculated with such leukemia. $\mathbf{C} \mathbf{R}$ Hebd Seances Acad Sci., [S.l.], v. 10, n. 246, p. 1.626-1.628, mar., 1958.

MORRISON, C.; LAHTEENMAKI, R. Public biotech 2018-the numbers. Nature Biotechnology, [S.l.], v. 37, p. 714-721, 2019.

OLIVEIRA, L. B.; RUSSO, S. L.; MARQUES, L. G. A.; GOMILA, J. M. V.; Technological productivity on control of Boophilus Microplus tick: A Patentometric Study. International Journal of Advanced Engineering Research and Science, v. 6, Issue-2, 2019.

SANTOS, Marcio de Miranda et al. Prospecção de tecnologias de futuro: métodos, técnicas e abordagem. Parcerias Estratégicas, [S.I.], n. 19, 2004.

SENTER, P. D. Potent antibody drug conjugates for cancer therapy. Curr Opin Chem Biol., [S.l.], v. 13, p. 235-244, 2009.

WAKANKAR, A. et al. Analytical methods for physicochemical characterization of antibody drug conjugates. mAbs, [S.I.], v. 3, n. 2, p. 161-172, 2011. DOI:10.4161/mabs.3.2.14960.

\section{Sobre os Autoras}

\section{Lana Grasiela Alves Marques}

E-mail: lanagrasiela@gmail.com

Doutorado.

Endereço profissional: Instituto de Comunicação e Informação Científica e Tecnológica em Saúde. Laboratório de Informação Científica e Tecnológica em Saúde. Av. Brasil, n. 4.365, Manguinhos, Rio de Janeiro, RJ. CEP: 21040-900.

\section{Fátima de Cássia Evangelista de Oliveira}

E-mail: cassiadefatima3006@gmail.com

Doutorado.

Endereço profissional: Departamento de Fisiologia e Farmacologia, Universidade Federal do Ceará, C.P. 3157, Fortaleza, CE. CEP: 60430-270. 


\section{Rejane Ramos de Machado}

E-mail: Rejane.machado@icict.fiocruz.br

Doutorado.

Endereço profissional: Instituto de Comunicação e Informação Científica e Tecnológica em Saúde. Laboratório de Informação Científica e Tecnológica em Saúde. Av. Brasil, n. 4.365, Manguinhos, Rio de Janeiro, RJ. CEP: 21040-900.

\section{Lidiane dos Santos Carvalho}

E-mail: lidiane.carvalho@icict.fiocruz.br

Doutorado.

Endereço profissional: Instituto de Comunicação e Informação Científica e Tecnológica em Saúde. Laboratório de Informação Científica e Tecnológica em Saúde. Av. Brasil, n. 4.365, Manguinhos, Rio de Janeiro, RJ. CEP: 21040-900.

\section{Claudia do Ó Pessoa}

E-mail: cpessoa@ufc.br

Doutorado.

Endereço profissional: Departamento de Fisiologia e Farmacologia, Universidade Federal do Ceará, C.P. 3157, Fortaleza, CE. CEP: 60430-270. 